Georgia State University

ScholarWorks @ Georgia State University

2016

\title{
Family Correlates of Daughter's and Son's Locus of Control Expectancies during Childhood
}

\author{
Erin Tully \\ Georgia State University, etully2@gsu.edu \\ Jackson M. Gray \\ Georgia State University, jgray32@student.gsu.edu
}

Sherryl H. Goodman

Emory University, psysg@emory.edu

Stephen Nowicki Jr.

Emory University

Follow this and additional works at: https://scholarworks.gsu.edu/psych_facpub

Part of the Psychology Commons

\section{Recommended Citation}

Tully, E. C., Gray, J. M., Goodman, S. H., \& Nowicki, S. (2016). Family correlates of daughter's and son's locus of control expectancies during childhood. Early Child Development and Care. doi: 10.1080/ 03004430.2015 .1137562 .

This Article is brought to you for free and open access by the Department of Psychology at ScholarWorks @ Georgia State University. It has been accepted for inclusion in Psychology Faculty Publications by an authorized administrator of ScholarWorks @ Georgia State University. For more information, please contact scholarworks@gsu.edu. 
Family Correlates of Daughter's and Son's Locus of Control Expectancies during Childhood

Erin C. Tully

Jackson M. Gray

Sherryl H. Goodman

Steve Nowicki, Jr.

\section{Author Notes}

Erin C. Tully, Departments of Psychology at Emory University and Georgia State University; Address: Georgia State University; P.O. Box 5010, Atlanta, GA 30302-5010; Phone: 404-413-5096; E-mail: etully2@gsu.edu.

Jackson M. Gray, Department of Psychology, Georgia State University; Address:

Georgia State University; P.O. Box 5010, Atlanta, GA 30302-5010; Phone: 404-413-5086; Email: jgray32@student.gsu.edu.

Sherryl H. Goodman, Department of Psychology, Emory University; Address: 36 Eagle Row, PAIS Building, Atlanta, GA 30322; Phone: 404-727-4134; E-mail: psysg@emory.edu. Steve Nowicki, Department of Psychology, Emory University; Address: 36 Eagle Row, PAIS Building, Atlanta, GA 30322; E-mail: snowick@emory.edu.

Correspondence concerning this article should be addressed to Erin Tully. Research conducted at Emory University and Georgia State University. 


\begin{abstract}
Children who expect they can bring about good outcomes and avoid bad outcomes tend to experience more personal successes. Little is known about factors that contribute to these 'control expectancies'. The purpose of the present study was to determine whether children's internal control expectancies occur in the context of parents' internal control expectancies, low family strain, and high family cohesiveness and whether these factors are more strongly related to daughters' than sons' control expectancies. A community sample of 85 children aged 9 to 11 years old and their parents ( 85 mothers; 63 fathers) completed rating scales. Fathers' more internal control expectancies and mothers' reports of fewer family strains were associated with daughters' but not sons' greater internal control expectancies, and greater family cohesiveness was related to both daughters' and sons' internal control orientations. These findings suggest that family factors may contribute to children's, particularly daughters', development of internal control expectancies.
\end{abstract}

Keywords: locus of control, parenting, family cohesion, family strain, gender, father. 
Family Correlates of Daughter's and Son's Locus of Control Expectancies during Childhood Children's beliefs that they can control their own fate - that they can bring about positive outcomes and avoid negative outcomes - exert powerful influence over their academic successes, relationship satisfaction, and positive health outcomes (e.g., Bolger \& Patterson, 2001; Gale, Batty, \& Deary, 2008; Kalechstein \& Nowicki, 1997; Nowicki \& Duke, in press). The more children believe reinforcement is contingent on their own behaviour or personal characteristics the more internally oriented they are said to be; the more children perceive that reinforcements are due to external factors, such as chance, fate, or powerful others, the more externally oriented they are. Generalized control expectations have generated considerable research attention since Rotter (1966) first introduced the construct nearly fifty years ago, but surprising little of it has focused on the origins of control expectancies.

Rotter $(1954,1966,1990)$ theorized about the origins of locus of control orientation within a social learning framework; he posited that these expectancies form as people draw inferences about contingencies between their behaviour and reinforcements in the social environment. Nowicki and Segal (1974) further theorized that control expectancies are malleable to social learning influences during childhood and that the family environment provides an important context for these social learning influences. However, the specific family factors associated with children's internal locus of control expectancies have yet to be reliably identified.

The purpose of this study is to evaluate empirical support for theorized family factors that may contribute to children's locus of control orientations. We also propose that family factors are more influential contributors to daughters' than sons' control expectancies given evidence that girls tend to be more observant of others' behaviours and emotions (e.g., Dadds et al., 2008; 
Rudolph \& Hammen, 1999) and parents tend to use more interpersonally-oriented socialization practices with daughters than sons (e.g., Fivush, Brotman, Buckner, \& Goodman, 2000; Leaper, 2002).

Social learning theorists have posited that vicarious learning is a powerful social learning mechanism in children and that children model both behaviors and thought patterns (Bandura, 1986). Bandura (1999) provided evidence that children are more likely to model their parent's behaviour than the behaviour of other adults, and we propose that children may model their parent's control expectancies. Only a few studies have investigated whether parents and children have similar locus of control orientations. Ollendick (1979) investigated whether fourth graders (9-year-olds) and their parents have similar locus of control orientations and found small to moderate positive associations between daughters' locus of control orientations and both their mother's and father's locus of control, but sons' locus of control orientations were not related to their mother's or father's locus of control. Chandler, Wolf, Cook, and Dugovics (1980) studied a sample of fifth graders (approximately 10-year-olds) who were selected for having extremely high or low levels of academic achievement-related locus of control. They found that children's generalized locus of control scores were positively related to mother's locus of control, but they did not report differences in this association for girls and boys or the association between children's and father's generalized locus of control. The findings suggest that children and parents may tend to have similar locus of control orientations during middle childhood and that daughters may be more likely to model parent's control expectancies. Indeed, girls tend to be more perceptive of other's feelings and motivations than boys (e.g., Dadds et al., 2008) and parents encourage more interpersonal closeness and affiliation from their daughters than from 
their sons (Leaper \& Farkas, 2015). However, these few studies leave questions about differences in parent-child locus of control associations by gender of the child and the parent.

The experience of life stressors and strains is another powerful learning mechanism that has been theorized to contribute to more external locus of control orientations by making the environment seem chaotic and out of one's control (Rotter, 1966). Indeed, the accumulation of minor life strains and the experience of major family stressors, such as the absence of a father due to divorce or death, have been linked to children's more external control orientations (Duke \& Lancaster, 1976; Hetherington, 1972; Lancaster \& Richmond, 1983). Given girls tend to experience more affected by family stressors and strains (e.g., Rudolph \& Hammen, 1999), and girls may thus be more in tune with and affected by family stressors and strains. Moreover, mother's stress, relative to father's stress, has been found to be more strongly associated with family functioning (e.g., Delvecchio et al., 2014) and child outcomes (e.g., Crawford \& Manassis, 2001). These findings together suggest that more family strains, perhaps particularly strains experienced by mothers, may contribute to children's, particularly daughter's, more external control expectancies. Again, though, studies have not addressed questions about differences in associations between family strains and locus of control in sons and daughters or whether mothers versus fathers experience of family strains is more strongly related to children's locus of control.

Finally, families characterized by cohesion and acceptance may encourage children's exploration of their environment and allow them to learn about contingent reinforcement and punishment, thus influencing the development of internal locus of control orientations (Carton \& Nowicki, 1994). Indeed, higher levels of family cohesion have been associated with more internal control expectancies in preadolescents and adolescents (Nowicki \& Schneewind, 1982). 
We again expect that differences in how daughters and sons experience interpersonal relationships and are socialized in the family context may make family cohesion a stronger correlate of girls' than boys' locus of control orientations, but researchers have not reported gender differences in associations between family cohesion and children's locus of control.

Family socialization factors are particularly relevant during middle childhood. Parentchild relationships are more mutual and collaborative during middle childhood than during earlier developmental periods and are warmer and more agreeable than during preadolescence and adolescence (e.g., Maccoby, 1992; Shanahan, McHale, Crouter, \& Osgood, 2008). During this period, parents and children share mutual expectancies about their relationship that are based on a history of shared parent-child experiences (Collins et al., 2002; Maccoby, 1984). Furthermore, children's capacity for causal reasoning about others' behaviors and intentions improves dramatically across middle childhood and is typically highly proficient by the end of this period (Collins, Madsen, \& Susman-Stillman, 2002). Thus, children are typically cognitively connected with their parents during middle childhood and have the requisite skills for social learning by the end of this developmental period. The present study focuses on a developmental period at the end of middle childhood using a sample of nine- to eleven-year-old children.

Research on differences in how mothers and fathers interact with their children during middle childhood suggests maternal and paternal socialization factors may be differentially associated with children's control expectancies. For example, studies consistently find that mothers interact with their children more frequently, provide more care, and are more directive than fathers and that father-child interactions are more likely to occur during play interactions (Collins et al., 2002; Collins \& Russell, 1991; Russell \& Russell, 1987). Furthermore, mother's 
parenting behaviors, such as controlling and supportive parenting, have been found to be more predictive of children's self-cognitions, such as self-worth, than father's parenting behaviors during middle childhood (Laible \& Carlo, 2004). Thus, the present study includes measures of both mother's and father's control expectancies and reports of family strains as potential correlates of children's control expectancies.

In summary, social learning theory suggests children's control expectancies occur in the context of certain family characteristics that may affect children's learning about the contingencies that exist between their behavior and outcomes. However, the family correlates of children's control expectancies, especially differences in correlates for daughters and sons, are not well understood. Findings that girls tend to be more interpersonally oriented than boys during middle childhood and that parents tend to use family socialization practices more often with daughters than sons suggest that these family characteristics may shape daughters' locus of control expectancies more strongly than sons'. Moreover, research suggesting differences in mothers' and fathers' socialization practices supports the importance investigating parental correlates of children's control expectancies separately for mothers and fathers.

Based on the principles of social learning theory and findings that girls, compared to boys, tend to be more perceptive of other's motivations and affected by interpersonal and family factors (e.g., Dadds et al., 2008; Rudolph \& Hammen, 1999), we made the following three hypotheses. First, we hypothesized that children, especially daughters, would vicariously model their parents' locus of control expectancies, and, thus, daughter's and parent's control expectancies would be positively associated and more strongly associated than son's and parents' control expectancies. Although the one study that investigated mother's and father's control expectancies separately found that both were related to daughter's and not son's control 
expectancies (Ollendick, 1979), research on differences in mother's and father's parenting practices during middle childhood suggests maternal and paternal socialization factors may be differentially associated with control expectancies (e.g., Collins et al., 2002). We thus tested this first hypothesis using both mother's and father's control expectancies as potential correlates, but not make a specific prediction about differences in associations between mother's and father's locus of control and children's locus of control. Second, we hypothesized that children, especially daughters, in families with high levels of family strain may learn that the environment is uncontrollable and thus parents' reports of more family strains would be associated with their daughter's, and to a lesser extent their son's, more external control expectancies. Furthermore, given that mother's stress has been found to be more strongly associated with family factors and child functioning (e.g., Crawford \& Manassis, 2001; Delvecchio et al., 2014) than father's stress, we made the prediction that mother's strains, specifically, would be associated with daughter's control expectancies. Third, we hypothesized that children's behaviours would be more likely to elicit contingent reinforcement in cohesive family environments and thus hypothesized that high levels of family cohesion would be associated with children's, especially daughters', more internal control expectancies. In other words, we expected gender differences in associations between all three family factors and children's locus of control expectancies, with stronger associations for daughters than sons.

\section{Method}

\section{Participants}

Children $(N=85 ; 51.8 \%$ female $)$ aged 9 to 11 years old and their parents $(N=85$ mothers; $N=63$ fathers) were recruited from the community in a large urban area in the southeastern United States to participate in the study. Families were recruited from camps and 
after-school programs (21.2\%), two elementary schools (18.8\%), a university organised pool of families who agreed to participate in research studies (32.9\%), and word of mouth $(27.1 \%)$. Most children were Caucasian (71.8\%); 17.6\% were African American; and 10.6\% were other ethnicities (Asian, American Indian, or Hispanic). Seventy-six children (89.0\%) lived in twoparent (all with a mother and father) households, and 9 children $(10.5 \%)$ lived in single-mother families. Sixty-three of the 76 fathers $(82.3 \%)$ participated and all mothers participated. Most mothers were biological mothers $(n=82), 2$ were step-mothers, and 1 was an adoptive mother, and most participating fathers $(n=59)$ were biological fathers and 4 were step-fathers. The mean yearly family income of the sample was $\$ 86,000$, and $70.9 \%$ of mothers and $98.9 \%$ of fathers had at least a college degree.

\section{Measures}

Child measures. Children completed the Children's Nowicki-Strickland InternalExternal control scale (CNSIE; Nowicki, 2015a; Nowicki \& Strickland, 1973) to measure their locus of control orientation. The measure has been used in well over 1500 studies and has been supported a reliable and valid measure of children's expectancies (Furhnam \& Steele, 1993). The CNSIE consists of 40 yes/no questions that assess whether children attribute life events to internal or external causes (e.g. "Do you feel that when good things happen they happen because of hard work?” versus “Are some kids just born lucky?”). The CNSIE is scored by calculating the total number of items answered in the externally controlled direction, with higher scores indicating more externality. The measure has been found to have good internal consistency reliabilities (Chronbach's alpha between .65 and .70) and test-retest reliabilities over six-week and nine-month periods of $\alpha=.63$ and .67 , respectively with elementary school children 
(Nowicki \& Strickland, 1973). The internal consistency reliability was $\alpha=.70(\alpha=.65$ for girls; $\alpha=.74$ for boys) for the present study.

Children's perceptions of their family environments were measured using the Cohesion scale of the Real Form of the Family Environment Scale (FES; Moos, 1981). This 9-item scale measures the degree of commitment, help, and support family members provide to one another. Children decided if 9 statements (e.g., "Family members really help and support one another”) were true/mostly true of their family or false/mostly false of their family. Higher scores indicate greater family cohesion. The Cohesion scale has been found to have high internal consistency ( $\alpha$ $=.77$ ), with four-month test-retest reliabilities of .73 to .86 and twelve-month test-retest reliabilities of .66 to .78 (Moos, 1981). The internal consistency reliability in this study was $\alpha=$ $.69(\alpha=.70$ for girls; $\alpha=.68$ for boys $)$.

Parent measures. Parents completed the Adult Nowicki-Strickland Internal-External Locus of Control Scale (ANSIE; Nowicki \& Duke, 1974). The ANSIE contains 40 yes/no questions similar to those on the CNSIE, and higher scores indicate greater externality. Internal consistency reliabilities have been reported to be .69 (males) and .39 (females), and seven-week and one-year test-retest reliabilities were .65 and .56 , respectively. Internal consistency reliabilities in this sample were .65 (fathers) and .68 (mothers). Additional construct validity information compiled from over a thousand studies can be found in ANSIE manual (Nowicki, 2015b).

Family Inventory of Life Events and Changes (FILE). Mothers and fathers also completed the FILE (McCubbin, Wilson, \& Patterson, 1979), which is a 71-item checklist of family-related stressors, hardships, and strains that were experienced in their family in the past year. Families are often dealing with several stressors simultaneously, and the FILE provides an 
index of the "pile-up" of stressors. The 17-item intra-family strains index was selected for this study, as it is the most reliable and valid scale and most directly measures the construct of interest. This scale measures family changes such as increased arguments among family members, family members having emotional or substance use problems, and difficulties parenting children. A count of the number of strains experienced in the previous year was used; higher scores indicate more family strain. It has a reported Cronbach's alpha of .81 and four to five week test-retest reliabilities around .80 (McCubbin \& McCubbin, 1988). The Cronbach's alpha in the present study was .78 for mothers' report and .79 for fathers' report.

\section{Procedure}

The study was reviewed, approved, and monitored by the institutional review board at the university where the study was conducted. All parents provided written, informed consent for their own participation. Parents provided written permission for their children to participate, and children provided verbal assent. A researcher met with each child at their home, school, or afterschool program. The researcher was available to answer questions and ensure thorough completion of the measures by the children. Mothers and fathers completed the measures during the researcher's visit to the home, or they completed and returned the questionnaires by mail.

\section{Results}

\section{Descriptive Statistics}

IBM® SPSS $®$ Statistics, Version 21 was used to conduct statistical analyses to test study hypotheses. Data were first inspected for errors, outliers, and distributional assumptions (Tabachnick \& Fidell, 2013); no study variables had outlier data points (i.e., 3 standard deviations above or below the mean) and the children's locus of control (the outcome variable) had a normal distribution, $D(84)=0.08, p=.20$. Means, standard deviations, and zero-order 
correlations for main study variables are presented in Table 1.

Series of $t$-tests, ANOVAs, and chi-square tests were run to test for differences in mean levels or frequencies of study variables by whether or not father's participated in the study, recruitment source, and children's gender. There were significant differences between families with and without a participating father in children's gender (30\% girls for families without a participating father; $59 \%$ girls for families with a participating father), $X^{2}(83)=4.73, p=.03$, and children's ethnicity (52\% Caucasian and 39\% African American for families without a participating father; $79 \%$ Caucasian and 9.5\% African American for families with a participating father), $X^{2}(83)=11.12, p=.004$. There were no significant differences in children's age, mother's education, yearly family income, recruitment source, children's locus of control, mother's locus of control, family cohesion, or mother's reports of family strains. Children recruited from the subject pool $(M=9.88, S D=1.00)$ were significantly younger than children recruited from the schools $(M=10.69, S D=0.57), F(3,81)=3.03, p=.03$. Mothers of participating boys $(M=4.27, S D=2.17)$ reported higher levels of family strains than mothers of participating girls $(M=2.78, S D=1.83), t(83)=2.54, p=.01$. There were no other significant gender or recruitment source differences in study variables.

\section{Tests of Study Hypotheses}

The three hypotheses were tested using three separate multiple linear regression analyses. In each regression equation, children's locus of control orientation was regressed on the effects of the mean-centered predictor family variables (i.e., mother's and father's locus of control, mother's locus of control, mother's and father's reports of family strains, and family cohesion), child's gender, and the interaction of the predictor variable and child's gender. Additionally, given our sample included some non-biological parents (e.g., stepparents) and there is some 
evidence supporting the heritability of locus of control orientations (Miller \& Rose, 1982), we included whether the parent had a biological relation to the child as a statistical control. We also included the child's ethnicity as a statistical control given some evidence supporting more externality in Caucasian compared to African American children (Miller, Fitch, \& Marshall, 2003). Significant interactions were followed up with tests of simple slopes to determine the magnitude and significance of the effects in daughters and sons separately.

The first hypothesis was supported with father's locus of control but not mother's locus (Table 2). Child's gender moderated the association between fathers' locus of control orientation and children's locus of control orientation. This interaction is depicted in Figure 1, panel A. Tests of simple slopes showed that father's more internal locus of control orientations were significantly associated with daughter's more internal locus of control, $b=0.65, S E=0.24, \beta=$ $.46, p=.008$, and father's locus of control was not significantly associated with son's locus of control, $b=-0.15, S E=0.28, \beta=-.10, p=.60$. Child's gender did not moderate the association between mother's locus of control orientations and their children's locus of control orientations, and there was no main effect of mother's locus of control on children's locus of control.

The second hypothesis was supported (Table 3). Child's gender moderated the association between mother's report of family strains and child's locus of control (Figure 1, panel B). Mother's report of more family strains was significantly associated with daughter's more external locus of control, $b=-0.83, S E=0.41, \beta=-.39, p=.009$, and was not significantly associated with their son's locus of control, $b=0.07, S E=0.24, \beta=.04, p=.78$. Child's gender did not moderate the association between father's reports of family strains and child's locus of control, and the main effect of father's reports of family strains on child's locus of control was 
not significant, although the effect was moderate in magnitude, with father's reports of more family strains related to children's more external locus of control.

Lastly, the third hypothesis was partially supported. The interaction between child's gender and child's perceptions of family cohesion was not significant, but the main effect of child's perceptions of family cohesion on children's locus of control was significant (Table 4). Greater family cohesion was associated with higher internal locus of control orientation in the full sample, and the association did not differ significantly for girls and boys.

In summary, daughters' higher internal locus of control expectancies were associated with fathers' higher internal locus of expectancies, mothers' (and almost fathers') reports of fewer family strains, and their own perceptions of greater family cohesion. Sons' higher internal locus of control expectancies were only associated with their own perceptions of greater family cohesion.

\section{Discussion}

In spite of the considerable evidence that internality in children is associated with greater success academically, personally, and socially than is externality, relatively little is known about the family correlates of internal and external control expectancies (Carton \& Nowicki, 1994). The purpose of the present study was to test the extent to which a set of theory-based constructs, parental locus of control, family strains and perceived family cohesion, are associated with children's locus of control orientation and to determine if these family factors are more strongly associated with girls' than boys' control expectancies.

We found that fewer mother-reported family strains and father's higher internal control expectancies were associated with daughter's but not son's higher internal control orientations. In addition, children's report of greater cohesive family environments was related to both 
daughter's and son's internal locus of control orientations. A parent's locus of control and experience of family strains likely influence their child's locus of control expectancies through social learning mechanisms that require the child to observe and make inferences about their parent's behaviours and experiences, skills that are typically more nurtured and thus advanced in girls than boys during middle childhood (e.g., Rose \& Rudolph, 2006). Family cohesion, on the other hand, is expected to facilitate a child's learning about contingent reinforcement by providing an environment that supports the child's independent interactions with the environment (Carton \& Nowicki Jr, 1994; Parke \& Buriel, 2006), and this mechanism does not require the same perspective-taking skills.

We expected that daughters' locus of control expectancies would be more strongly associated with their mother's and father's locus of control than would sons' locus of control, but we found that the only significant parent-child control expectancies association was between father's and daughter's expectancies. Our finding might be explained by social learning theory, which posits that modeling of behaviours and cognitions is more successful when the model is perceived as having power over resources the child desires (Bandura, 1986). Fathers are often perceived to have more power and authority than mothers (Radin, 1981), and daughters may be more likely to model their father's than their mother's locus of control. Furthermore, fathers importance in their daughter's development, for example their disordered eating behaviours, internalizing problems, and nonverbal cognitive abilities, is well documented in the literature (Coley, 1998; Eme \& Danielak, 1995; Hetherington, Camara, \& Featherman, 1983; Mitchell, Booth, \& King, 2009). Ollendick (1979) found that daughters', and not sons', control expectancies were related to their mother's and their father's control expectancies in a sample that was similar to our sample in the age of the children but was different in that the sample was 
recruited from a lower socioeconomic status school and included only two-parent families with participating mothers and fathers. Together these findings suggest that fathers and daughters have similar control expectancies, and additional research on associations between mothers and daughters control expectancies is warranted.

The particular importance of mother's perceptions of family strains for girl's locus of control is consistent with findings that mothers are more emotionally expressive (Garner, Robertson, \& Smith, 1997) and talk about feelings more often (Kuebli \& Fivush, 1992) with daughters than sons and studies supporting greater impact of mother's stress than father's stress on family functioning (e.g., Delvecchio et al., 2014). Daughters may be particularly aware of their mother's strains and the effects of the strains on mother's emotional state, and daughters' social learning about contingences in the environment may in turn be particularly affected by mother's experience of family strains.

To summarize, one way to interpret our findings is that the two family factors that most likely exert their influence on children's control expectancies through vicarious social learning mechanisms were related only to daughters' control expectancies, whereas the family factor that likely exerts its influence by providing a context for direct personal learning about reinforcement contingencies was related to daughters' and sons' control expectancies. Our study further suggests that daughters' social learning about control expectancies are influenced by fathers' control expectancies and mothers' experiences of strains.

It is important to note our study focused on generalized control beliefs. It would also be important to understand family correlates of children's beliefs about their control over specific aspects of their lives, such as their academic achievement. Although some studies have been published on that question, most have relied on unvalidated measures of these specific control 
expectancies (cf. Ahlin \& Lobo Antunes, 2015). Nowicki and Duke (2015) have criticized researchers for their proclivity to construct new locus of control scales with unknown psychometric qualities, which has led to the creation of literally hundreds of scales that are purported to measure the locus of control construct but are not shown to relate to the more established instruments. In contrast, we relied on a standardized locus of control scale that has been used in over a thousand studies and has been shown to tap generalized control expectancies.

\section{Future Directions/Implications}

The findings from this study support the potential importance of family factors in children's internal control expectancies. Prospective studies are needed to investigate gender differences in associations between these family factors and the development of locus of control expectancies from early to middle childhood in order to clarify how these processes unfold across time. It will also be important to investigate family factors that may have greater influence on boys' development of locus of control expectancies, such as parent's fostering of achievement and goal attainment or other parental socialization practices that are used more often with sons than daughters (e.g., Leaper, 2000). Lastly, studies may investigate moderators of the association between mother's and daughter's control expectancies, such as mother's parenting practices and family composition, to provide help clarify why Ollendick (1979) found a significant association between mother's and daughter's locus of control and our study did not.

\section{Limitations}

Several limitations of the study should be noted. First, we assessed family factors and children's locus of control at one point in time, and we thus do not know that the family factors preceded and contributed to the development of children's locus of control. Children's locus of control may conversely influence family characteristics, locus of control and family 
characteristics may have bidirectional influence, or the associations may be due to a third factor, such as genetic influences. Second, although most of our effects were moderate to strong in magnitude and our sample size was sufficient to detect these effects, our sample size is relatively

small. This may have limited detection of more subtle effects and gender differences, such as the effect of father's report of family strains on children's locus of control, which was not statistically significant but had a moderate effect size. Third, the families were primarily Caucasian and well educated and the findings may not generalize to other populations. Fourth, children's locus of control and family cohesion were both assessed with child-report measures, and reporter biases may have inflated their association. Fifth, the locus of control measures had relatively low internal consistency reliabilities.

\section{Conclusion}

Children's expectations that reinforcements and punishments are contingent on their own behaviour or personal characteristics, as opposed to being a product of external factors, are associated with their positive outcomes in all essential domains of functioning. Relatively little is known about the family correlates of these internal control expectancies. The present study identified several family-related correlates of children's locus of control that are consistent with theories of children's social learning about contingent reinforcements. Importantly, we found that these factors tend to be stronger correlates of daughters' than sons' control expectancies, suggesting the importance of accounting for children's gender in future investigations of mechanisms that affect children's development of internal control expectancies. Identifying factors that correlate with children's internal and external control expectancies is an important step toward the goal of constructing programs that facilitate the development of appropriate internality in children. 


\section{References}

Ahlin, E. M., \& Lobo Antunes, M. J. (2015). Locus of control orientation: Parents, peers, and place. Journal of Youth and Adolescence, 44, 1803-1818. doi: 10.1007/s10964-015-02539

Bandura, A. (1986). Social foundations of thought and action: A social cognitive theory. Englewood Cliffs, NJ: Prentice-Hall.

Bandura, A. (1999). Social cognitive theory of personality. In. L. A. Pervin, \& Oliver, J. P. (Eds.), Handbook of Personality: Theory and Research (pp. 154-196). New York: The Guildford Press.

Bolger, K. E., \& Patterson, C. J. (2001). Pathways from child maltreatment to internalizing problems: Perceptions of control as mediators and moderators. Development and Psychopathology, 13(4), 913-940.

Carton, J. S., \& Nowicki Jr, S. (1994). Antecedents of individual differences in locus of control of reinforcement: A critical review. Genetic, Social and General Psychology Monographs, 120(1), 31-81.

Chandler, T. A., Wolf, F. M., Cook, B., \& Dugovics, D. A. (1980). Parental correlates of locus of control in fifth graders: An attempt at experimentation in the home. Merrill-Palmer Quarterly of Behavior and Development, 26(3), 183-195. doi:10.2307/23083613

Coley, R. L. (1998). Children's socialization experiences and functioning in single-mother households: The importance of fathers and other men. Child Development, 69(1), 219230.

Collins, W. A., Madsen, S. D., \& Susman-Stillman, A. (2002). Parenting during middle childhood. In M. H. Bornstein, \& M.H. Bornstein (Eds.), Handbook of parenting: Vol. 1: 
Children and Parenting (2nd ed., pp. 73-101). Mahwah, NJ: Lawrence Erlbaum Associates.

Collins, W. A., \& Russell, G. (1991). Mother-child and father-child relationships in middle childhood and adolescence: A developmental analysis. Developmental Review, 11(2), 99_ 136. doi:10.1016/0273-2297(91)90004-8

Crawford, A. M., \& Manassis, K. (2001). Familial predictors of treatment outcome in childhood anxiety disorders. Journal of the American Academy of Child \& Adolescent Psychiatry, 40(10), 1182-1189. doi:10.1097/00004583-200110000-00012

Dadds, M. R., Hunter, K., Hawes, D. J., Frost, A. D. J., Vassallo, S., Bunn, P., Merz, S., \& Masry, Y. E. (2008) A measure of cognitive and affective empathy in children using parent ratings. Child Psychiatry and Human Development, 39(2), 111-122.

Delvecchio, E., Di Riso, D., Chessa, D., Salcuni, S., Mazzeschi, C., \& Laghezza, L. (2014). Expressed emotion, parental stress, and family dysfunction among parents of nonclinical Italian children. Journal of Child and Family Studies, 23(6), 989-999. doi:10.1007/s10826-013-9754-x

Duke, M. P., \& Lancaster, W. (1976). A note on locus of control as a function of father absence. The Journal of Genetic Psychology, 129(2), 335-336.

doi:10.1080/00221325.1976.10534046

Eme, R. F., \& Danielak, M. H. (1995). Comparison of fathers of daughters with and without maladaptive eating attitudes. Journal of Emotional and Behavioral Disorders, 3(1), 4045. doi:10.1177/106342669500300105 
Fivush, R., Brotman, M. A., Buckner, J. P., \& Goodman, S. H. (2000). Gender differences in parent-child emotion narratives. Sex Roles, 42(3-4), 233-253. doi:10.1023/a:1007091207068

Furnham, A., \& Steele, H. (1993). Measuring locus of control: A critique of general, children's, health- and work-related locus of control questionnaires. British Journal of Psychology, $84,443-479$.

Gale, C. R., Batty, G. D., \& Deary, I. J. (2008). Locus of control at age 10 years and health outcomes and behaviors at age 30 years: The 1970 British Cohort study. Psychosomatic Medicine, 70(4), 397-403. doi:10.1097/PSY.0b013e31816a719e

Garner, P. W., Robertson, S., \& Smith, G. (1997). Preschool Children's Emotional Expressions with Peers: The Roles of Gender and Emotion Socialization. Sex Roles: A Journal of Research, 36 (11-12), 675-691.

Hetherington, E. M. (1972). Effects of father absence on personality development in adolescent daughters. Developmental Psychology, 7(3), 313-326. doi:10.1037/h0033339

Hetherington, E. M., Camara, K. A., \& Featherman, D. L. (1983). Achievement and intellectual functioning of children from one-parent households. In J. T. Spence (Ed.), Achievement and Achievement Motives. (pp. 205-284). San Francisco: Freeman Press.

Kalechstein, A. D., \& Nowicki, S., Jr. (1997). A meta-analytic examination of the relationship between control expectancies and academic achievement: An 11-yr follow-up to Findley and Cooper. Genetic, Social, and General Psychology Monographs, 123(1), 27-56.

Kuebli, J., \& Fivush, R. (1992). Gender differences in parent-child conversations about past emotions. Sex Roles, 27 (11-12), 683-698. doi: 10.1007/BF02651097 
Laible, D. J., \& Carlo, G. (2004). The differential relations of maternal and paternal support and control to adolescent social competence, self-worth, and sympathy. Journal of Adolescent Research, 19(6), 759-782. doi:10.1177/0743558403260094

Lancaster, W. W., \& Richmond, B. O. (1983). Perceived locus of control as a function of father absence, age, and geographic location. The Journal of Genetic Psychology, 143(1), 5156. doi:10.1080/00221325.1983.10533533

Leaper, C. (2000). Gender, affiliation, assertion, and the interactive context of parent-child play. Developmental Psychology, 36(3), 381-393. doi:10.1037/0012-1649.36.3.381

Leaper, C. (2002). Parenting girls and boys. In M. H. Bornstein, \& M. H. Bornstein (Eds.), Handbook of parenting: Vol. 1: Children and parenting (2nd ed., pp. 189-225). Mahwah, NJ: Lawrence Erlbaum Associates.

Leaper, C., \& Farkas, T. (2015). The socialization of gender during childhood and adolescence. In J. E. Grusec, P.D. Hastings, J. E. Grusec, \& P. D. Hastings (Eds.), Handbook of Socialization: Theory and Research (2nd ed., pp. 541-565). New York, NY: Guilford Press.

Maccoby, E. E. (1984). Middle childhood in the context of the family. In W. A. Collins (Ed.), Development during middle childhood: The years from six to twelve (pp. 184239).Washington, DC: National Academy of Sciences.

Maccoby, E. E. (1992). The role of parents in the socialization of children: An historical overview. Developmental Psychology, 28(6), 1006-1017. doi:10.1037/00121649.28.6.1006

McCubbin, H. I., \& McCubbin, M. A. (1988). Family Systems Assessment. In P. Karoly (Ed.), Handbook of Child Health Assessment (pp. 227-261). New York: Wiley-Interscience. 
McCubbin, H. I., Wilson, L., \& Patterson, J. M. (1979). Family Inventory of Life Events and Changes (FILE) . St. Paul, Minnesota: Family Social Science, University of Minnesota.

Miller, C. A., Fitch, T., \& Marshall, J. L. (2003). Locus of control and at-risk youth: A comparison of regular education high school students and students in alternative schools. Education, 123(3), 548-552.

Miller, J. Z., \& Rose, R. J. (1982). Familial resemblance in locus of control: A twin-family study of the internal-external scale. Journal of Personality and Social Psychology, 42(3), 535540. doi:10.1037/0022-3514.42.3.535

Mitchell, K. S., Booth, A., \& King, V. (2009). Adolescents with nonresident fathers: Are daughters more disadvantaged than sons? Journal of Marriage and Family, 71(3), 650662. doi:10.1111/j.1741-3737.2009.00624.x

Moos, R. H. (1981). Family environment scale manual. Palo Alto, CA: Consulting Psychologist Press.

Nowicki, S. (2015a). A Manual for the Adult Nowicki Strickland Internal External Control Scale (Unpublished manuscript). Department of Psychology, Atlanta, GA: Emory University.

Nowicki, S. (2015b). A Manual for the Children's Nowicki Strickland Internal External Control Scale (Unpublished manuscript). Department of Psychology, Atlanta, GA: Emory University.

Nowicki, S., \& Duke, M. P. (1974). A locus of control scale for college as well as non-college adults. Journal of Personality Assessment, 38, 133-137.

Nowicki, S., \& Duke, M. P. (in press). Foundations of locus of control research to be published. In Frank Infurna, \& John W. Reich (Eds.), Perceived control: Theory, research, and practice in the first 50 years. Oxford University Press. 
Nowicki, S., \& Schneewind, K. (1982). Relation of family climate variables to locus of control in German and American students. Journal of Genetic Psychology, 141(2), 277 -286.

Nowicki, S., \& Segal, W. (1974). Perceived parental characteristics, locus of control orientation, and behavioral correlates of locus of control. Developmental Psychology, 10(1), 33-37. doi:10.1037/h0035563

Nowicki, S., \& Strickland, B. R. (1973). A locus of control scale for children. Journal of Consulting \& Clinical Psychology, 40, 148-154.

Ollendick, D. G. (1979). Parental Locus of Control and the Assessment of Children's Personality Characteristics. Journal of Personality Assessment, 43(4), 401-405.

Parke, R. D., \& Buriel, R. (2006). Socialization in the family: Ethnic and ecological perspectives. In N. Eisenberg, W. Damon, R.M. Lerner, N. Eisenberg, W. Damon, \& R. M. Lerner (Eds.), Handbook of Child Psychology: Vol. 3, Social, Emotional, and Personality Development (6th ed., pp. 429-504). Hoboken, NJ: John Wiley \& Sons.

Radin, N. (1981). The role of the father in cognitive, academic, and intellectual development. In M. E. Lamb (Ed.), The Role of the Father in Child Development (2nd ed., pp. 379-428). New York: Wiley.

Rose, A. J., \& Rudolph, K. D. (2006). A review of sex differences in peer relationship processes: Potential trade-offs for the emotional and behavioral development of girls and boys. Psychological Bulletin, 132(1), 98-131. doi:10.1037/0033-2909.132.1.98

Rotter, J. B. (1954). Social Learning and Clinical Psychology. Englewood Cliffs, NJ: PrenticeHall. 
Rotter, J. B. (1966). Generalized expectancies for internal versus external control of reinforcement. Psychological Monographs: General and Applied, 80(1), 1-28. doi:10.1037/h0092976

Rotter, J. B. (1990). Internal versus external control of reinforcement: A case history of a variable. American Psychologist, 45(4), 489-493. doi:10.1037/0003-066X.45.4.489

Rudolph, K. D., \& Hammen, C. (1999). Age and gender as determinants of stress exposure, generation, and reactions in youngsters: A transactional perspective. Child Development, 70(3), 660-677. doi:10.1111/1467-8624.00048

Russell, G., \& Russell, A. (1987). Mother-child and father-child relationships in middle childhood. Child Development, 58(6),1573-1585. doi:10.2307/1130696

Shanahan, L., McHale, S. M., Crouter, A. C., \& Osgood, D. W. (2008). Linkages between Parents' differential treatment, youth depressive symptoms, and sibling relationships. Journal of Marriage and Family, 70(2), 480-494. doi: 10.1111/j.1741-3737.2008.00495.x

Tabachnick, B. G., \& Fidell, L. S. (2013). Using Multivariate Statistics (6th ed.). Boston: Pearson. 
Table 1

Means, Standard Deviations, and Zero-Order Relations between all Variables

\begin{tabular}{|c|c|c|c|c|c|c|c|c|c|c|}
\hline & \multirow[b]{2}{*}{$N$} & \multirow[b]{2}{*}{$M$} & \multirow[b]{2}{*}{$S D$} & \multicolumn{7}{|c|}{ Correlations } \\
\hline & & & & 1. & 2. & 3. & 4. & 5. & 6. & 7. \\
\hline 1. Age & 85 & 10.25 & 0.96 & & .01 & -.13 & .21 & .02 & -.10 & .17 \\
\hline 2. Children's Locus of Control & 85 & 14.70 & 4.76 & -.01 & & $-.39 * *$ & $.47 * *$ & -.05 & $.34 *$ & $.33 *$ \\
\hline 3. Children's Perceptions of Family Cohesion & 85 & 7.01 & 1.73 & .04 & $-.38^{*}$ & & -.05 & .20 & -.28 & $-.38 *$ \\
\hline 4. Father's Locus of Control & 63 & 7.78 & 3.40 & -.09 & -.04 & $.61 * *$ & & .10 & .26 & .01 \\
\hline 5. Mother's Locus of Control & 85 & 7.93 & 3.44 & -.03 & -.11 & $.27 *$ & .11 & & -.10 & -.02 \\
\hline 6. Father's Report of Family Strains & 63 & 2.59 & 2.04 & -.17 & .16 & .22 & $-.48 *$ & $.44^{*}$ & & .19 \\
\hline 7. Mother's Report of Family Strains & 85 & 3.49 & 2.76 & -.02 & .04 & -.002 & .09 & $.34^{*}$ & $.44 *$ & \\
\hline
\end{tabular}

Notes. Correlations for girls are above the diagonal and for boys are below the diagonal. * $p<.05, * * p<.01$. 
Table 2

Tests of the Moderating Effects of Child Gender on Associations between Mothers' and Fathers' Locus of Control and Children's Locus of Control

\begin{tabular}{|c|c|c|c|c|c|}
\hline Predictor & $\Delta R^{2}$ & $b$ & $S E$ & $\beta$ & $p$ \\
\hline \multicolumn{6}{|l|}{ Mother's Locus of Control (LOC) } \\
\hline Step 1 & .01 & & & & .81 \\
\hline Mother's biological relation to child & & -0.72 & 1.16 & -.07 & .53 \\
\hline Child's ethnicity & & 0.21 & 0.76 & .03 & .78 \\
\hline Step 2 & .01 & & & & .58 \\
\hline Child's gender & & -0.69 & 1.08 & -.08 & .53 \\
\hline LOC & & -0.15 & 0.16 & -.11 & .34 \\
\hline Step 3 & .004 & & & & .55 \\
\hline Mother's LOC X child's gender & & -0.19 & 0.32 & -0.10 & .55 \\
\hline \multicolumn{6}{|l|}{ Father's Locus of Control (LOC) } \\
\hline Step 1 & .02 & & & & .50 \\
\hline Father's biological relation to child & & 1.48 & 1.25 & .15 & .24 \\
\hline Child's ethnicity & & -0.08 & 0.92 & -.01 & .93 \\
\hline Step 2 & .05 & & & & .24 \\
\hline Child's gender & & -0.05 & 1.35 & -.01 & .97 \\
\hline LOC & & 0.32 & 0.19 & .23 & .09 \\
\hline Step 3 & .07 & & & & .03 \\
\hline Father's LOC X child's gender & & -0.80 & .36 & -.37 & .03 \\
\hline
\end{tabular}

Notes. We report models with $0=$ female and $1=$ male; $0=$ biological mother and $1=$ nonbiological mother; $0=$ Caucasian, $1=$ African American, $2=$ Other ethnicities. $b$ is the unstandardized estimate. $S E$ is the standard error. $\beta$ is the standardized estimate. 
Table 3

Tests of the Moderating Effects of Child Gender on Associations between Mothers' and Fathers' Reports of Family Strains and Children's Locus of Control

\begin{tabular}{|c|c|c|c|c|c|}
\hline Predictor & $\Delta R^{2}$ & $b$ & $S E$ & $\beta$ & $p$ \\
\hline \multicolumn{6}{|l|}{ Mother's Report of Family Strains (FS) } \\
\hline Step 1 & .01 & & & & .80 \\
\hline Mother's biological relation to child & & -0.69 & 1.20 & -.06 & \\
\hline Child's ethnicity & & 0.34 & 0.79 & .05 & .67 \\
\hline Step 2 & .04 & & & & .17 \\
\hline Child's gender & & -1.21 & 1.09 & -.13 & .27 \\
\hline Mother's FS & & 0.34 & 0.20 & 0.20 & .08 \\
\hline Step 3 & .05 & & & & .05 \\
\hline Mother's FS X child's gender & & -0.83 & 0.41 & -0.39 & .04 \\
\hline \multicolumn{6}{|l|}{ Father's Report of Family Strains (FS) } \\
\hline Step 1 & .02 & & & & .50 \\
\hline Father's biological relation to child & & 1.35 & 1.25 & .14 & .28 \\
\hline Child's ethnicity & & .47 & 1.04 & .06 & .65 \\
\hline Step 2 & .05 & & & & .20 \\
\hline Child's gender & & 0.49 & 1.39 & .05 & .72 \\
\hline Father's FS & & 0.57 & 0.32 & .24 & .08 \\
\hline Step 3 & .01 & & & & .52 \\
\hline Father's FS X child's gender & & -.56 & 0.78 & -.13 & .47 \\
\hline
\end{tabular}

Notes. We report models with $0=$ female and $1=$ male; $0=$ biological mother and $1=$ nonbiological mother; $0=$ Caucasian, 1 = African American, $2=$ Other ethnicities. $b$ is the unstandardized estimate. $S E$ is the standard error. $\beta$ is the standardized estimate. 
Table 4

Tests of the Moderating Effects of Child Gender on Associations between Children's Perceptions of Family Cohesion and Children's Locus of Control

\begin{tabular}{lccccc}
\multicolumn{1}{c}{ Predictor } & $\Delta R^{2}$ & $b$ & $S E$ & $\beta$ & $p$ \\
\hline $\begin{array}{l}\text { Children's Perceptions of Family Cohesion } \\
\text { Step 1 }\end{array}$ & .01 & & & & .80 \\
$\quad$ Child's ethnicity & & 0.34 & 0.80 & .05 & .67 \\
Step 2 & .12 & & & & .001 \\
$\quad$ Child's gender & & 1.17 & 1.03 & .12 & .26 \\
$\quad$ Family cohesion & & $\mathbf{- 1 . 0 7}$ & $\mathbf{. 2 9}$ & $\mathbf{- . 3 9}$ & $<.001$ \\
Step 3 & .01 & & & & .36 \\
$\quad$ Family cohesion X child's gender & & -0.56 & 0.60 & -.14 & .36 \\
\hline
\end{tabular}

Notes. We report models with $0=$ female and $1=$ male; $0=$ biological mother and $1=$ nonbiological mother; $0=$ Caucasian, $1=$ African American, $2=$ Other ethnicities. $b$ is the unstandardized estimate. $S E$ is the standard error. $\beta$ is the standardized estimate. 

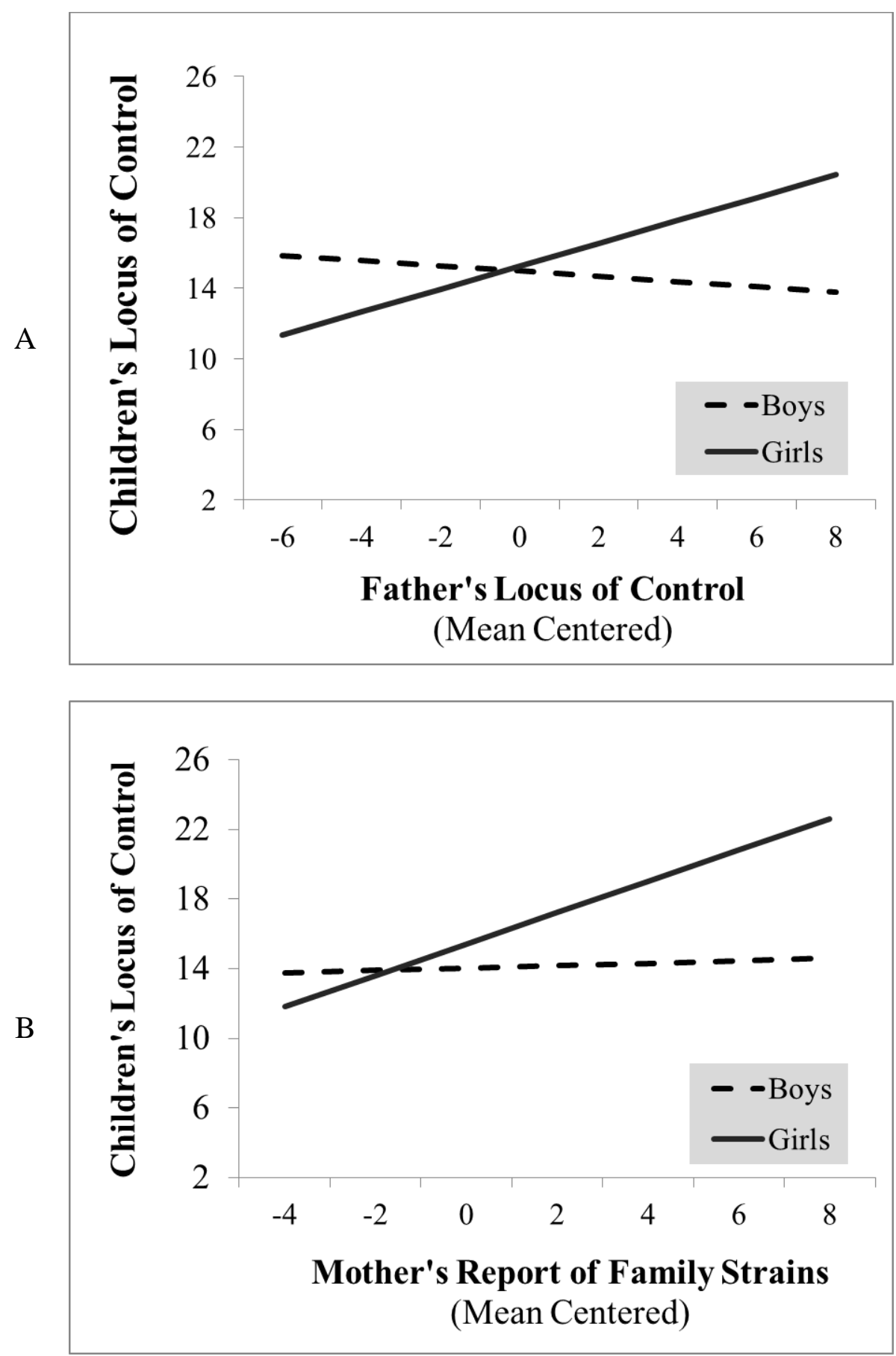

Figure 1. Graphs depicting significant interactions between children's gender and (A) father's locus of control predicting children's locus of control and (B) mother's reports of family strain predicting children's locus of control. 


\section{Biographical Notes}

Erin C. Tully, Ph.D. is an assistant professor in the Department of Psychology at Georgia State University. Her research focuses on how parent-child factors, including children's perceptions of parents' emotions and behaviors, contribute to children's psychological development.

Jackson M. Gray, B.A. is a graduate student in the clinical psychology programme in the Department of Psychology at Georgia State University. His research interests include familyrelated factors that facilitate healthy child development.

Sherryl H. Goodman is a Samuel Candler Dobbs Professor in the Department of Psychology at Emory University. Her research is focused on developmental psychopathology with a specific interest in the mechanisms by which mothers with depression may transmit psychopathology to their children.

Stephen Nowicki is Candler Professor Emeritus at Emory University. His research interests focus on personality and skill factors that impact on relating, especially locus of control and nonverbal communication. 